\title{
Bulk Phase Relations, Conductivity, and Transparency in Novel Bixbyite Transparent Conducting Oxide Solution in the Cadmium-Indium-Tin Oxide System
}

\author{
Daniel R. Kammler, ${ }^{*, \dagger}$ Thomas O. Mason, ${ }^{*, \dagger}$ and Kenneth R. Poeppelmeier, ${ }^{*,}$ \\ Department of Materials Science and Engineering, Department of Chemistry, and Materials Research Center, \\ Northwestern University, Evanston, Illinois 60208
}

\begin{abstract}
A novel transparent conducting bixbyite solid solution $\mathrm{In}_{2-2 x}(\mathrm{Cd}, \mathrm{Sn})_{2 x} \mathrm{O}_{3}\left(0<x<0.34\right.$ at $\left.1175^{\circ} \mathrm{C}\right)$ has been discovered. Four-point dc-conductivity varies widely with $x$ and the $[\mathrm{Sn}] /[\mathrm{Cd}]$ ratio with a maximum in excess of $1800 \mathrm{~S} / \mathrm{cm}(x=$ $0.05,[\mathrm{Sn}] /[\mathrm{Cd}]=9)$ and a minimum too low to be measured $(x=0.05,[\mathrm{Sn}] /[\mathrm{Cd}]=0)$. The optical gap measured along the line $\mathrm{In}_{2-2 x} \mathrm{Cd}_{x} \mathrm{Sn}_{x} \mathrm{O}_{3}$ remains constant near $3 \mathrm{eV}$ while transparency decreases with increasing $x$ possibly because of free carrier absorption. Four-point dc-conductivities measured from biphasic samples prepared by varying the $[\mathrm{Sn}] /[\mathrm{Cd}]$ ratio suggest that the solution extends between the $\mathrm{CdO}-\mathrm{In}_{2} \mathrm{O}_{3}$ and $\mathrm{SnO}_{2}-\mathrm{In}_{2} \mathrm{O}_{3}$ binaries for small $x$. As $x$ increases, the solution width decreases and is found to exist only over a small range of $[\mathrm{Sn}] /[\mathrm{Cd}]$ ratios slightly greater than unity near $x=0.34$. Single-phase bixbyite samples subjected to a reduction anneal showed increased conductivity and slightly higher optical gaps, possibly as a consequence of the Moss-Burstein shift. The ratio of the reduced to as-fired conductivities for specimens prepared along the line $\mathrm{In}_{2-2 x} \mathrm{Cd}_{x} \mathrm{Sn}_{x} \mathrm{O}_{3}$ decreased with increasing $x$. This suggests that for small $x$ electrons are generated by oxygen vacancies while at larger $x$ the electron population is fixed by a Sn excess (i.e., $[\mathrm{Sn}] /[\mathrm{Cd}]>1$ ).
\end{abstract}

\section{Introduction}

$\mathrm{T}$ RANSPARENT conducting oxides (TCOs) are a class of materials that transmit visible radiation and conduct electricity. They find application as transparent electrodes in numerous applications such as photovoltaics, flat panel displays, heat reflective coatings on energy-efficient windows, and electrochromics such as smart mirrors. The present industrial TCO of choice is tin-doped indium oxide (ITO). Commercial ITO has been prepared with conductivities of $5600 \mathrm{~S} / \mathrm{cm}$, mobilities of $28.3 \mathrm{~cm}^{2} /(\mathrm{V} \cdot \mathrm{s})$, and carrier densities of $1.2 \times 10^{21}{ }^{1}$ As areas increase in solar cells and flat panel displays, the electrode resistivity must decrease to prevent increased $I^{2} R$ losses associated with the larger areas. Increasing the carrier density will increase conductivity at the expense of transparency as a result of increased free carrier absorption. ${ }^{2}$ Consequently, it is necessary to find novel TCOs with higher mobilities or determine how to increase the mobility in preexisting TCOs.

H. U. Anderson—contributing editor

Manuscript No. 188298. Received August 25, 2000; approved January 16, 2001 This research was partially supported by the MRSEC program of the National Science Foundation (Contract No. DMR 9632472) through the Materials Research Center (MRC) located at Northwestern University and used the central facilities of the MRC. Additional support was obtained from the Department of Energy administered through the National Renewable Energy Lab under Subcontract No AAD-9-186685. One of the authors (D.R.K.) was supported through a National Science Foundation raduate Fellowship.

${ }^{*}$ Member, American Ceramic Society.

${ }^{\dagger}$ Department of Materials Science and Engineering and Materials Research Center.

Department of Chemistry and Materials Research Center.
Reports of high mobility TCOs produced at the laboratory scale include $60 \mathrm{~cm}^{2} /(\mathrm{V} \cdot \mathrm{s})$ for $\mathrm{Cd}_{2} \mathrm{SnO}_{4},{ }^{2} 100 \mathrm{~cm}^{2} /(\mathrm{V} \cdot \mathrm{s})$ for $\mathrm{Cd}_{2} \mathrm{SnO}_{4},{ }^{3}$ $44.2 \mathrm{~cm}^{2} /(\mathrm{V} \cdot \mathrm{s})$ for $\mathrm{CdIn}_{2} \mathrm{O}_{4},{ }^{2}$ and $103 \mathrm{~cm}^{2} /(\mathrm{V} \cdot \mathrm{s})$ for ITO. ${ }^{4}$ At present, the crystal chemical, microstructural, and processing considerations involved in producing high-mobility TCOs are not well understood. One recurring feature present in the best TCOs is the presence of continuous edge sharing octahedra of $\mathrm{Cd}^{2+}, \mathrm{In}^{3+}$, and $\mathrm{Sn}^{4+}$. Shannon et al. ${ }^{5}$ noted a strong correlation between this structural feature and transparent conduction in their study of single crystals of $\mathrm{CdSnO}_{3}, \mathrm{Cd}_{2} \mathrm{SnO}_{4}, \mathrm{In}_{2} \mathrm{TeO}_{6}$, and $\mathrm{CdIn}_{2} \mathrm{O}_{4}$.

In addition to traditional n-type TCOs, p-type TCOs are required for new applications such as transparent electronics, IR applications, and high-temperature and radiation hard electronics. ${ }^{6}$ To date, much of the research on p-type TCOs has focused on materials with the delafossite structure such as $\mathrm{CuAlO}_{2}{ }^{7}$ or $\mathrm{CuScO}_{2}{ }^{8}$ Recently, p-type $\mathrm{ZnO}$ with hole concentrations near $10^{20} 1 / \mathrm{cm}^{3}$ was prepared via a metastable codoping process incorporating N-Ga-N associates. ${ }^{6,9,10}$ Previously, the phenomenon of codoping has been known to give rise to extensive n-type TCO solid solutions. Palmer et al. ${ }^{11}$ discovered a large bixbyite solid solution $\operatorname{In}_{2-2 x} \mathrm{Zn}_{x} \mathrm{Sn}_{x} \mathrm{O}_{3}\left(0<x<0.40\right.$ at $\left.1250^{\circ} \mathrm{C}\right)$. More recently, Ambrosini et al. ${ }^{12}$ have attempted to produce p-type $\mathrm{In}_{2-2 x} \mathrm{Zn}_{x} \mathrm{Sn}_{x} \mathrm{O}_{3}$ by adding excess $\mathrm{Zn}$ in hopes of creating acceptors. While these authors did not produce p-type $\operatorname{In}_{2-2 x} \mathrm{Zn}_{x} \mathrm{Sn}_{x} \mathrm{O}_{3}$, they did substantially reduce the electron concentration by adding excess Zn, which suggests that this strategy may be successful in other systems or when used in combination with a metastable synthesis route.

The similar chemistry of $\mathrm{Cd}$ and $\mathrm{Zn}$ led us to investigate whether an analogous solution $\mathrm{In}_{2-2 x} \mathrm{Cd}_{x} \mathrm{Sn}_{x} \mathrm{O}_{3}$ existed. Such a solution would be interesting because it contains continuous edge sharing octahedra of $\mathrm{Cd}^{2+}, \mathrm{In}^{3+}$, and $\mathrm{Sn}^{4+}$, which Shannon speculated to be a key component of high-quality n-type TCOs. ${ }^{5}$ Furthermore, it may be possible to produce p-type $\mathrm{In}_{2-2 x} \mathrm{Cd}_{x} \mathrm{Sn}_{x} \mathrm{O}_{3}$ using the same techniques (i.e., add excess $\mathrm{Cd}$ to $\left.\mathrm{In}_{2-2 x} \mathrm{Cd}_{x} \mathrm{Sn}_{x} \mathrm{O}_{3}\right)$ that had failed to produce $\mathrm{p}$-type $\mathrm{In}_{2-2 x} \mathrm{Zn}_{x} \mathrm{Sn}_{x} \mathrm{O}_{3}$.

In this paper we report the bulk phase relations for the solution $\mathrm{In}_{2-2 x}(\mathrm{Cd}, \mathrm{Sn})_{2 x} \mathrm{O}_{3}$. In addition we report the change in conductivity, thermopower, optical gap (estimated from the absorption edge measured in a diffuse reflectance experiment), and transparency for both as-fired and reduced specimens. In addition to reporting these data, we present a simple defect model that explains the carrier generation mechanism in this solid solution.

\section{Experimental Procedure}

Samples were prepared by mixing the appropriate quantities of $\mathrm{CdO}, \mathrm{InO}_{1.5}$ (note, $\mathrm{InO}_{1.5}$ is used instead of $\mathrm{In}_{2} \mathrm{O}_{3}$ throughout the paper so that the mole percent of the parent oxides- $\mathrm{CdO}, \mathrm{InO}_{1.5}$, and $\mathrm{SnO}_{2}$ - are the same as the cation percent of $\mathrm{Cd}$, In, and $\mathrm{Sn}$ in all of the formulas), and $\mathrm{SnO}_{2}(>99.99 \%$ purity cation basis, Aldrich Chemical Co., Inc.) in an agate mortar and pestle under acetone. The mixed powders were pressed in a $1 / 4$-in. die at 150 $\mathrm{MPa}$ to a thickness between 1.5 and $3 \mathrm{~mm}$. The pellets were loaded 
into a cylindrical crucible and surrounded by a bed of their constituent powders to prevent contamination from the crucible wall and suppress volatilization. The cylindrical crucible was covered by a tight-fitting alumina closed-end tube as an added measure to reduce voltilization. The pellets were calcined initially at $1000^{\circ} \mathrm{C}$ for $20-24 \mathrm{~h}$ and then air-quenched. The quenched pellets were reground, repelletized, and loaded back into the furnace for a second firing at $1175^{\circ} \mathrm{C}$ for $20-24 \mathrm{~h}$ to increase density and reach equilibrium. As more In was replaced by $\mathrm{Cd}$ and $\mathrm{Sn}$, additional regrinding and firing steps (at $1175^{\circ} \mathrm{C}$ ) were necessary to reach equilibrium. Specimens of four nominal com-

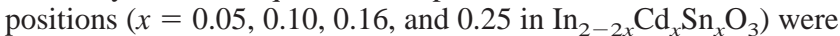
dissolved in a 50/50 (by volume) mixture of concentrated hydrochloric and nitric acid and subjected to inductively coupled plasma atomic emission spectroscopy (ICP-AES) to obtain the as-fired $\mathrm{In} / \mathrm{Cd}$ ratio. Atomic absorption standards consisting of 1000 $\mu \mathrm{g} / \mathrm{mL} \mathrm{Cd}$ and In dissolved in $1 \mathrm{wt} \% \mathrm{HNO}_{3}$ (Aldrich Chemical Co., Inc.) were used to calibrate the ICP-AES instrument. Obtaining the $\mathrm{Sn}$ concentration proved impossible because it was determined that $\mathrm{Sn}$ did not dissolve (the white precipitate left behind from the acid reaction was found to consist solely of phase-pure rutile $\mathrm{SnO}_{2}$ by XRD). By assuming that the overall composition change during firing was entirely the result of $\mathrm{Cd}$ voltilization, the final compositions were obtained to within $1 \%$ error.

Phase purity was established via $\mathrm{Cu} K_{\alpha} \mathrm{X}$-ray powder diffraction (XRD) (Rigaku, Danvers, MA). A nickel filter was used to remove the $\mathrm{Cu} K_{\beta}$ contribution from the diffraction pattern. Powders were scanned between $10^{\circ}$ and $70^{\circ}$ in $2 \theta$ for routine phase analysis. Scans in $2 \theta$ for individual bixbyite peaks used in determining the lattice constant along the solution were obtained on a $\mathrm{Cu} K_{\alpha 1}$ diffractometer with a LiF monochromator. Exact peak locations were determined by fitting these data using the software package Peakfit ${ }^{13}$ and correcting their locations for zero shift and off-axis displacement error using a silicon internal standard. These corrected peak locations were then used to calculate the lattice constants by the method of least squares using the software package POLSQ. ${ }^{14}$

Direct-current conductivity was measured at room temperature using a standard four-point probe apparatus (Cascade Microtech, Beaverton, OR) and a constant current source and digital multimeter (Models 224 and 195A Keithly, Cleveland, OH). The following equation was used to calculate the conductivity of the sintered pellets:

$$
\sigma=\frac{1}{\rho}=\frac{1}{\left(\frac{V}{I}\right) w C\left(\frac{d}{s}\right) F\left(\frac{w}{s}\right)}
$$

Here $\sigma$ is the conductivity, $I$ is the current supplied between the two outer probes (typically $50 \mathrm{~mA}$ ), $V$ is the potential drop measured across the inner two electrodes, $d$ is the sample diameter, $s$ is the spacing between the probe tips $(1.016 \mathrm{~mm}), w$ is the sample thickness, and $C$ and $F$ are correction factors for the finite sample diameter and thickness. ${ }^{15}$ Table I lists the as-fired densities for specimens used in this study. Since the densities of specimens in this study ranged between $45.9 \%$ and $60.1 \%$ of theoretical, the conductivities were corrected using the Bruggeman symmetric medium equation for continuous interconnected three-dimensional porosity as described by McLachlan et al.: ${ }^{16}$

$$
\sigma_{\text {measured }}=\sigma_{\text {true }}\left(1-1.5 f_{\text {porosity }}\right)
$$

Here $\sigma_{\text {measured }}$ is the measured conductivity, $\sigma_{\text {true }}$ is the conductivity of the fully dense specimen, and $f_{\text {porosity }}$ is the volume fraction of porosity. Room-temperature thermopower data were obtained by sandwiching specimens between two gold foil contacts. One gold contact was in thermal equilibrium with a $23 \mathrm{~W}$ soldering iron and the other was in thermal equilibrium with a cylindrical steel slug $(2 \mathrm{~cm}$ tall and $2 \mathrm{~cm}$ in diameter) that rested on an insulating ceramic brick. A type $\mathrm{S}(\mathrm{Pt}, \mathrm{Pt} / 10 \% \mathrm{Rh})$ thermocouple was welded to each of the gold contacts. A thermal gradient was created by switching the soldering iron on and
Table I. Densities of Specimens Used in This Study

\begin{tabular}{lc}
\hline Nominal Composition in $\operatorname{In}_{2-2 x}(\mathrm{Cd}, \mathrm{Sn})_{2 x} \mathrm{O}_{3}$ & $\begin{array}{c}\text { Density }(\% \text { of } \\
\text { theoretical })\end{array}$ \\
\hline$x=0$ pure $\mathrm{In}_{2} \mathrm{O}_{3}$ & 45.9 \\
$x=0.05[\mathrm{Cd}]=[\mathrm{Sn}]$ & 53.3 \\
$x=0.10[\mathrm{Cd}]=[\mathrm{Sn}]$ & 52.6 \\
$x=0.16[\mathrm{Cd}]=[\mathrm{Sn}]$ & 55.8 \\
$x=0.225[\mathrm{Cd}]=[\mathrm{Sn}]$ & 58.2 \\
$x=0.25[\mathrm{Cd}]=[\mathrm{Sn}]$ & 56.5 \\
$x=0.275[\mathrm{Cd}]=[\mathrm{Sn}]$ & 54.3 \\
$x=0.30[\mathrm{Cd}]=[\mathrm{Sn}]$ & 60.1 \\
$x=0.05[\mathrm{Cd}]=[\mathrm{Sn}]+0.04$ & 57.1 \\
$x=0.05[\mathrm{Sn}]=[\mathrm{Cd}]+0.04$ & 53.2 \\
$x=0.11[\mathrm{Cd}]=[\mathrm{Sn}]+0.04$ & 53.6 \\
$x=0.11[\mathrm{Sn}]=[\mathrm{Cd}]+0.04$ & 55.0 \\
$x=0.17[\mathrm{Cd}]=[\mathrm{Sn}]+0.04$ & 52.8 \\
$x=0.17[\mathrm{Sn}]=[\mathrm{Cd}]+0.04$ & 53.9 \\
$x=0.23[\mathrm{Cd}]=[\mathrm{Sn}]+0.04$ & 52.5 \\
$x=0.23[\mathrm{Sn}]=[\mathrm{Cd}]+0.04$ & 52.9 \\
$x=0.29[\mathrm{Cd}]=[\mathrm{Sn}]+0.04$ & 56.5 \\
$x=0.29[\mathrm{Sn}]=[\mathrm{Cd}]+0.04$ & 57.5 \\
$x=0.35[\mathrm{Cd}]=[\mathrm{Sn}]+0.04$ & 55.5 \\
$x=0.35[\mathrm{Sn}]=[\mathrm{Cd}]+0.04$ & 55.8 \\
\hline
\end{tabular}

allowing it to heat to $120^{\circ}-150^{\circ} \mathrm{C}$. At this point the soldering iron was switched off and the thermal gradient was allowed to decay. Temperature and voltage (measured between the two platinum leads) were measured every $15 \mathrm{~s}$ using a digital multimeter and scanner (Keithly Models 195A and 705) controlled with a personal computer. Thermopower was obtained by fitting the temperature and voltage gradient data with a least-squares fit as the sample approached equilibrium (i.e., the thermal gradient was less than $20^{\circ} \mathrm{C}$ and the average absolute temperature was $60^{\circ} \mathrm{C}$ ) as required by the equation

$$
Q=-\lim _{\Delta T \rightarrow 0}(\Delta V / \Delta T)
$$

The thermopower was corrected for the contribution of the platinum leads ${ }^{17}$ using the polynomial fit of Hwang. ${ }^{18}$

Since thin films of these materials were unavailable, optical data were obtained from diffuse reflectance measurements. In a diffuse reflectance experiment the nonspecular component of reflection from a bulk sample (e.g., the pellet surface in this case) is measured relative to a standard using an integrating sphere. This measurement provides information that is analogous to transmission. ${ }^{19}$ The absorption edge onset (determined by the intersection of a line drawn through the sloped part of the transition region between high and low transmission and another line drawn through the low-transmission part of the spectra) was used to estimate an optical gap. The diffuse reflectance was measured between 800 and $200 \mathrm{~nm}$ using a double-beam spectrophotometer with an integrating sphere (Cary 1E with Cary 1/3 attachment, Varian Walnut Creek, CA). Base line spectra were collected using pressed polytetrafluoroethylene (PTFE) powder compacts (Varian Part No. 04-101439-00) located in both the sample and reference beams. The pellets were mounted on a blackened sample mask. Data were collected at $600 \mathrm{~nm} / \mathrm{min}$ using an interval of $1 \mathrm{~nm}$, an averaging time of $0.1 \mathrm{~s}$, and a signal bandwidth of $3 \mathrm{~nm}$.

After conductivity, diffuse reflectance, and thermopower data were collected, single-phase bixbyite samples were subjected to a reduction anneal at $400^{\circ} \mathrm{C}$ for $6 \mathrm{~h}$ in $4 \% \mathrm{H}_{2}, 96 \% \mathrm{~N}_{2}$ in hopes of increasing conductivity. The annealed samples were then subjected to the same battery of tests again (i.e., four-point dc conductivity, diffuse reflectance, and thermopower).

\section{Results and Discussion}

The high temperatures required to reach equilibrium in this study are the cause of substantial Cd loss as a result of the high vapor pressure of $\mathrm{Cd}$ above compositions within this system at 
$1175^{\circ} \mathrm{C}$. Figure 1 shows a pseudoternary composition plot that illustrates the location of samples used in this study. The straight line represents the formula $\operatorname{In}_{2-2 x} \mathrm{Cd}_{x} \mathrm{Sn}_{x} \mathrm{O}_{3}$ and the other compositions are $2 \% \mathrm{Cd}$ or $2 \% \mathrm{Sn}$ rich (e.g., a sample with $x=0.20$ in the formula $\mathrm{In}_{2-2 x} \mathrm{Cd}_{x} \mathrm{Sn}_{x} \mathrm{O}_{3}$ corresponds to [In] $=80$, [Cd] $=$ $[\mathrm{Sn}]=10$; a Cd-rich sample with $x=0.2$ corresponds to [In] $=$ $80,[\mathrm{Cd}]=12$, and $[\mathrm{Sn}]=8$; a Sn-rich sample with $x=0.20$ corresponds to $[\mathrm{In}]=80,[\mathrm{Cd}]=8$, and $[\mathrm{Sn}]=12$ ). The $2 \% \mathrm{SnO}_{2}$ rich samples were composed of bixbyite and a small amount of $\mathrm{SnO}_{2}$ (rutile) while the $2 \% \mathrm{CdO}$ rich samples were composed of bixbyite and a small amount of a ternary spinel phase $\mathrm{Cd}_{1+x} \mathrm{In}_{2-2 x} \mathrm{Sn}_{x} \mathrm{O}_{4}$ reported previously. ${ }^{20}$ After sufficient firing the compositions (nominal) prepared along the line $\mathrm{In}_{2-2 x} \mathrm{Cd}_{x} \mathrm{Sn}_{x} \mathrm{O}_{3}$ contained only bixbyite. Figure 2 shows representative XRD patterns for the as-fired Cd-rich, Sn-rich, and phase-pure bixbyite compositions shown in Fig. 1. The dominant phase in all three patterns is bixbyite. Extra lines resulting from the presence of rutile $\left(\mathrm{SnO}_{2}\right)$ and spinel $\left(\mathrm{Cd}_{1+x} \mathrm{In}_{2-2 x} \mathrm{Sn}_{x} \mathrm{O}_{4}\right)$ are marked with squares and circles, respectively. Table II shows the total firing time at $1175^{\circ} \mathrm{C}$ required to obtain phase-pure bixbyite for these specimens. Figure 1 also shows the results of the ICP-AES analysis of the nominal and postfired $x=0.05,0.10$, 0.16 , and 0.25 compositions along the line $\operatorname{In}_{2-2 x} \mathrm{Cd}_{x} \mathrm{Sn}_{x} \mathrm{O}_{3}$. In the case of the first three specimens, the as-fired and postfired composition points overlap. In the case of the $x=0.25$ composition, however, there was a measurable shift in composition. The increased firing time required to produce single-phase bixbyite with increasing $x$ along $\operatorname{In}_{2-2 x} \mathrm{Cd}_{x} \mathrm{Sn}_{x} \mathrm{O}_{3}$ and the increased composition change associated with these longer firing times suggest that the final fired composition of the single-phase bixbyite samples prepared with nominal stoichiometry $\operatorname{In}_{2-2 x} \mathrm{Cd}_{x} \mathrm{Sn}_{x} \mathrm{O}_{3}$ is increasingly (with $x$ ) richer in $\mathrm{Sn}$ (i.e., $[\mathrm{Sn}] /[\mathrm{Cd}]>1$ ).

Figure 3 shows the lattice constants of phase-pure bixbyite specimens quenched from $1175^{\circ} \mathrm{C}$ with nominal compositions given by the formula $\operatorname{In}_{2-2 x} \mathrm{Cd}_{x} \mathrm{Sn}_{x} \mathrm{O}_{3}$. The error in the lattice constants is $\sim 0.001 \AA$. This leads to an error of $x=0.02$ in $x$ so that the terminal solubility is somewhere between 0.32 and 0.35 with an average near 0.34 . The lattice constant changes only 0.006 $\AA$ for every 0.1 change in $x$. The relatively small changes in lattice constant are a consequence of the similarity of the ionic radii of $\mathrm{In}^{3+}$ and the average of $\mathrm{Sn}^{4+}$ and $\mathrm{Cd}^{2+}$ radii. Shannon ${ }^{21}$ reports ionic radii of $0.95,0.80$, and $0.69 \AA$ for $\mathrm{Cd}^{2+}, \mathrm{In}^{3+}$, and $\mathrm{Sn}^{4+}$ cations, respectively, in octahedral coordination. Thus the average $\mathrm{Cd}^{2+}$ and $\mathrm{Sn}^{4+}$ radius is $0.82 \AA$, which is only $0.02 \AA$ different from the $\mathrm{In}^{3+}$ cation radius.

To understand the conductivity trends for samples prepared in or near the bixbyite phase field it is necessary to have some idea of the defect chemistry responsible for conduction in this material. Table III shows the electroneutrality conditions that apply to specimens prepared at different locations within this phase field. It is generally accepted that the defect responsible for electron production in pure $\mathrm{InO}_{1.5}$ is the oxygen vacancy. ${ }^{22-24}$ The carrier

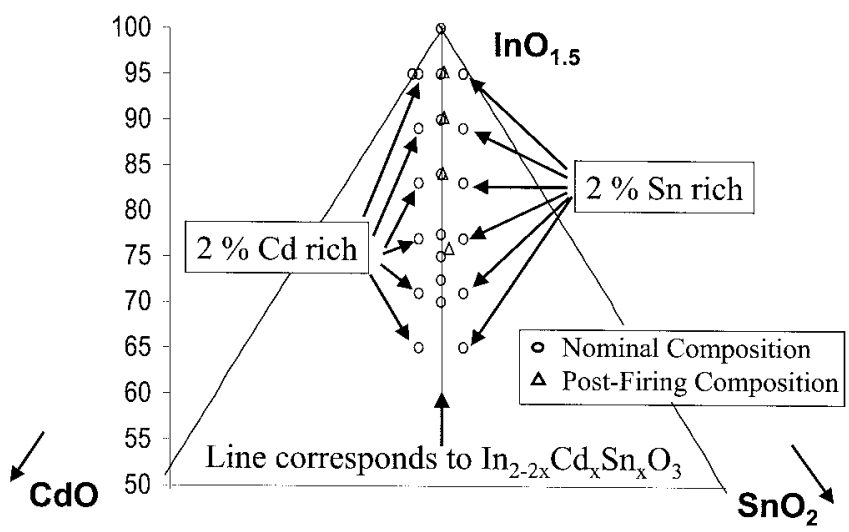

Fig. 1. Pseudoternary diagram illustrating initial and final (select specimens along $\mathrm{In}_{2-2 x} \mathrm{Cd}_{x} \mathrm{Sn}_{x} \mathrm{O}_{3}$ only) compositions prepared in this study.

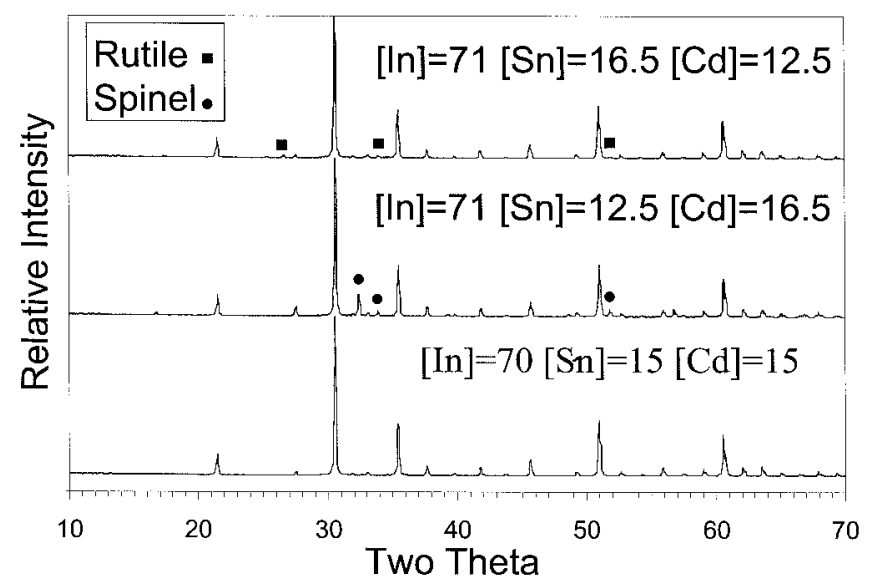

Fig. 2. XRD patterns of as-fired specimens with nominal compositions corresponding to the following: $[\mathrm{In}]=70,[\mathrm{Sn}]=[\mathrm{Cd}]=15$ $\left(\mathrm{In}_{2-2 x} \mathrm{Cd}_{x} \mathrm{Sn}_{x} \mathrm{O}_{3}\right) ;[\mathrm{In}]=71,[\mathrm{Sn}]=12.5,[\mathrm{Cd}]=16.5(2 \% \mathrm{Cd}$ rich $)$; and $[\mathrm{In}]=71,[\mathrm{Sn}]=16.5,[\mathrm{Cd}]=12.5(2 \% \mathrm{Sn}$ rich $) \mathrm{In}_{2-2 x}(\mathrm{Cd}, \mathrm{Sn})_{2 x} \mathrm{O}_{3}$.

Table II. Firing Times for Samples Prepared with Nominal Stoichiometry Given by $\mathrm{In}_{2-2 x} \mathrm{Cd}_{x} \mathrm{Sn}_{x} \mathrm{O}_{3}$

\begin{tabular}{lc}
\hline$x$ in $\operatorname{In}_{2-2 x} \mathrm{Cd}_{x} \mathrm{Sn}_{x} \mathrm{O}_{3}$ & $\begin{array}{r}\text { Total firing time } \\
\text { at } 1175^{\circ} \mathrm{C}(\mathrm{h})\end{array}$ \\
\hline 0.05 & 22 \\
0.10 & 49 \\
0.16 & 68 \\
0.225 & 92 \\
0.25 & 138 \\
0.275 & 92 \\
0.30 & 158 \\
\hline
\end{tabular}

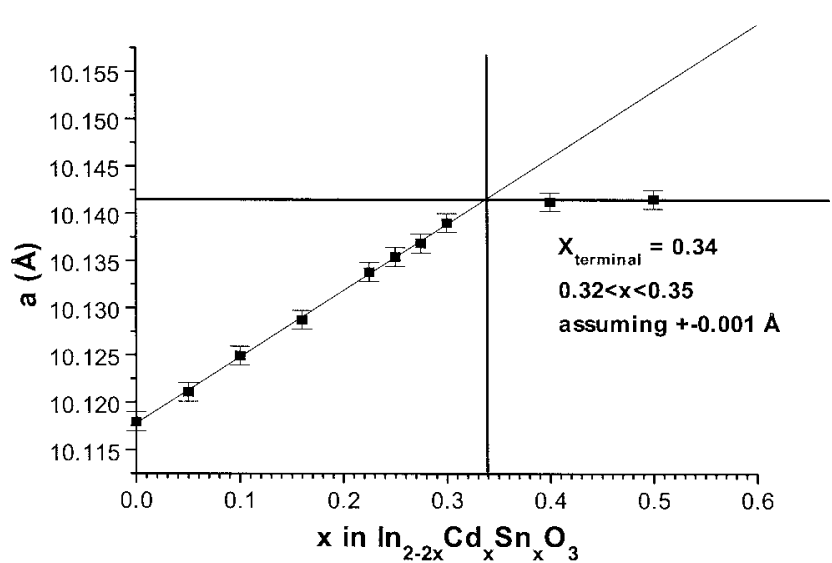

Fig. 3. Cell constants of single-phase bixbyite specimens with nominal composition given by $\operatorname{In}_{2-2 x} \mathrm{Cd}_{x} \mathrm{Sn}_{x} \mathrm{O}_{3}$ at $1175^{\circ} \mathrm{C}$.

density is a function of the oxygen pressure in accordance with the reaction

$$
\begin{aligned}
& \mathrm{O}_{\mathrm{O}}^{\times} \rightarrow V_{\mathrm{O}}^{*}+2 \mathrm{e}^{\prime}+\frac{1}{2} \mathrm{O}_{2} \\
& K_{\mathrm{OX}}=\left[V_{\mathrm{O}}^{*}\right] n^{2} P_{\mathrm{O}_{2}}^{1 / 2}
\end{aligned}
$$

As $\mathrm{SnO}_{2}$ is added to $\mathrm{InO}_{1.5}$ in small concentrations (i.e., on the order of $1 \%$ or less), Sn substitutes for $\mathrm{In}$ in $\mathrm{InO}_{1.5}$ to extrinsically dope the material at levels far exceeding the oxygen vacancy population. ${ }^{24}$ Thus the electroneutrality condition changes from that shown in the first row of Table III to that shown in the second 
Table III. Electroneutrality Conditions for Various Specimens within the Bixbyite Phase Field in the $\mathrm{CdO}-\mathrm{In}_{2} \mathrm{O}_{3}-\mathrm{SnO}_{2}$ System

\begin{tabular}{|c|c|}
\hline Specimen & Electroneutrality condition \\
\hline $\begin{array}{l}\text { Pure indium oxide (i.e., } \\
\left.\mathrm{In}_{2} \mathrm{O}_{3}\right)\end{array}$ & $2\left[V_{\mathrm{O}}^{* *}\right]=n$ \\
\hline $\begin{array}{l}\text { ITO at low doping level } \\
\quad(\text { e.g., }[\mathrm{In}]=99,[\mathrm{Sn}]=1)\end{array}$ & {$[\mathrm{Sn}]_{\mathrm{total}}=\left[\mathrm{Sn}_{\mathrm{In}}^{\cdot}\right]=n$} \\
\hline $\begin{array}{l}\text { Cd doped } \mathrm{In}_{2} \mathrm{O}_{3} \\
\text { Cd,Sn Co-substituted } \mathrm{In}_{2} \mathrm{O}_{3} \\
\left.\quad \text { (i.e., } \mathrm{In}_{2-2 x}(\mathrm{Cd}, \mathrm{Sn})_{2 x} \mathrm{O}_{3}\right)\end{array}$ & $\begin{array}{l}{\left[\mathrm{Cd}_{\mathrm{In}}^{\prime}\right]=2\left[V_{\mathrm{O}}^{* *}\right]} \\
\left(\left[\mathrm{Sn}_{\mathrm{In}}^{*}\right]-\left[\mathrm{Cd}_{\mathrm{In}}^{\prime}\right]\right)=n\end{array}$ \\
\hline
\end{tabular}

row. Hence the electron population is fixed by the Sn concentration and is insensitive to reduction. Further addition of $\mathrm{Sn}$ in $\mathrm{In}_{2} \mathrm{O}_{3}$ will result in the formation of reducible and irreducible defect complexes that cause the carrier density in ITO to become sensitive to oxygen pressure. ${ }^{24,25}$

We have attempted to dope $\mathrm{InO}_{1.5}$ with $\mathrm{CdO}$ by preparing a sample with a In:Cd ratio of 95:5 by the procedure described in the Experimental Procedure section. Powder XRD showed a twophase mixture of spinel $\mathrm{CdIn}_{2} \mathrm{O}_{4}$ and bixbyite $\mathrm{InO}_{15}$. The lattice constant was found to be $10.122 \AA$, which is slightly larger than Marezio's value of $10.117 \AA$ for pure $\mathrm{InO}_{1.5}{ }^{26}$ The increase in lattice constant suggests a small solubility of $\mathrm{CdO}$ in $\mathrm{InO}_{1.5}$, consistent with the findings of Morozova et al., who found a $1 \%$ solubility of $\mathrm{CdO}$ in $\mathrm{InO}_{1.5}{ }^{27}$ Furthermore, the increase in cell constant is expected since $\mathrm{Cd}^{2+}$ has a larger ionic radius than $\mathrm{In}^{3+}$ $\left(0.95\right.$ vs 0.80 in octahedral coordination $\left.{ }^{21}\right)$. Conductivity could not be measured on this sample because it was so insulating. An electroneutrality condition such as that shown in the third row of Table III might apply in this situation. Essentially $\mathrm{Cd}^{2+}$ doping for $\mathrm{In}^{3+}$ results in ionic compensation through the formation of additional oxygen vacancies, with the consequent reduction in electron population as per Eq. (4).

If both $\mathrm{CdO}$ and $\mathrm{SnO}_{2}$ are added to $\mathrm{InO}_{1.5}$, then the effective doping level may be thought of as the difference in concentration of the $\mathrm{Sn}$ and $\mathrm{Cd}$ on In sites as exemplified by the electroneutrality condition shown in the fourth row of Table III. Thus the carrier density and conductivity of the single-phase bixbyite samples with nominal stoichiometry corresponding to the formula $\mathrm{In}_{2-2 x} \mathrm{Cd}_{x} \mathrm{Sn}_{x} \mathrm{O}_{3}$ will be a sensitive function of their location within the ternary bixbyite phase field. The carrier density and conductivity of the Cd- and Sn-rich two-phase samples will be a sensitive function of the location of the phase boundaries of the bixbyite phase field within the ternary system $\mathrm{CdO}-\mathrm{InO}_{1.5}-\mathrm{SnO}_{2}$.

To make use of conductivity data arising from two-phase samples, the contribution of the second minority phase to the total conductivity must be taken into account. The minority spinel phase $\mathrm{Cd}_{1+x} \mathrm{In}_{2-2 x} \mathrm{Sn}_{x} \mathrm{O}_{4}$ present in the Cd-rich samples has been prepared in the same manor as the other samples in this study and found to have as-fired conductivities between $1600 \mathrm{~S} / \mathrm{cm}(x=0)$ and $2600 \mathrm{~S} / \mathrm{cm}(x=0.70) .{ }^{20}$ The fact that no conductivity could be measured despite the presence of the highly conducting spinel phase in the In:Cd 95:5 sample suggests that it is discontinuous and therefore unable to transport current through the sample. Since the mole percent of spinel $\mathrm{Cd}_{1+x} \mathrm{In}_{2-2 x} \mathrm{Sn}_{x} \mathrm{O}_{4}$ for all of the Cd-rich two-phase samples in this study is similar to that of the 95:5 In:Cd sample, we conclude that the conductivity in the Cd-rich samples is determined solely by the bixbyite phase. The conductivity of the Sn-rich two-phase samples is also determined solely by the bixbyite phase since the $\mathrm{SnO}_{2}$ second phase is a poor conductor with as-fired conductivities less than $0.01 \mathrm{~S} / \mathrm{cm}^{28}$ Since the volume fraction of the second phase was roughly constant for each of these samples, correction was made only for the volume fraction of porosity in the samples using the Bruggeman symmetric medium equation described in the Experimental Procedure section. ${ }^{16}$

Figure 4 shows the as-fired four-point conductivities of all three sets of samples. The conductivity of the Sn-rich samples decreases dramatically as $x$ increases. The conductivities of the Cd-rich

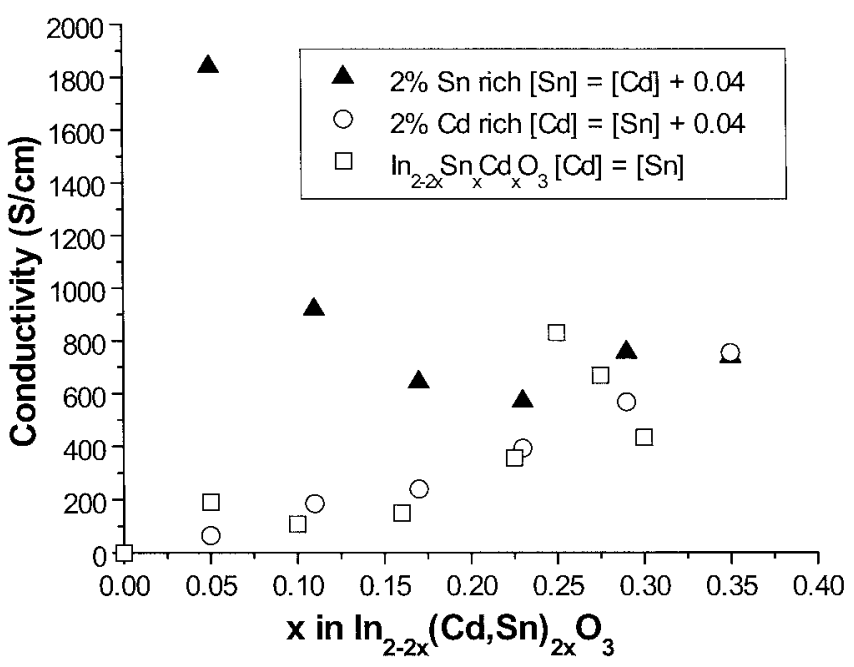

Fig. 4. Conductivity of samples shown in Fig. 1.

samples and the single-phase samples with nominal stoichiometry given by $\operatorname{In}_{2-2 x} \mathrm{Cd}_{x} \mathrm{Sn}_{x} \mathrm{O}_{3}$ increase gradually with $x$. Figure 5 shows a plot of the base 10 logarithm of the ratio of the $\mathrm{Sn}$-rich to Cd-rich conductivities as a function of $x$ in $\operatorname{In}_{2-2 x}(\mathrm{Cd}, \mathrm{Sn})_{2 x} \mathrm{O}_{3}$. The ratio changes smoothly from about 28 to an asymptotic value of 1 . This suggests that the bixbyite solution has substantial width for small $x$ (e.g., $x=0.01)$ in $\mathrm{In}_{2-2 x}(\mathrm{Cd}, \mathrm{Sn})_{2 x} \mathrm{O}_{3}$ and decreases in width to virtually a line for large $x$ (e.g., $x=0.34$ ). In other words, at small $x$ the solution extends substantially away toward the $\mathrm{CdO}-\mathrm{InO}_{1.5}$ binary as shown in Fig. 6, which shows a semiquantitative picture of the bixbyite phase field. The solution extends between the $\mathrm{CdO}-\mathrm{InO}_{1.5}$ and $\mathrm{SnO}_{2}-\mathrm{InO}_{1.5}$ binaries near the $\mathrm{InO}_{1.5}$ vertex of the $\mathrm{CdO}-\mathrm{InO}_{1.5}-\mathrm{SnO}_{2}$ system and narrows to a line as $x$ in $\mathrm{In}_{2-2 x}(\mathrm{Cd}, \mathrm{Sn})_{2 x} \mathrm{O}_{3}$ increases. In addition, as $x$ in $\mathrm{In}_{2-2 x}(\mathrm{Cd}, \mathrm{Sn})_{2 x} \mathrm{O}_{3}$ increases, the phase field moves to the right of the line defined by the formula $\operatorname{In}_{2-2 x} \mathrm{Cd}_{x} \mathrm{Sn}_{x} \mathrm{O}_{3}$. Justification for the movement of the bixbyite phase field off the line $\mathrm{In}_{2-2 x} \mathrm{Cd}_{x} \mathrm{Sn}_{x} \mathrm{O}_{3}$ is shown in Fig. 7.

Figure 7 shows the base 10 logarithm of the ratio of reduced to as-fired conductivities of the single-phase samples with nominal stoichiometry given by $\operatorname{In}_{2-2 x} \mathrm{Cd}_{x} \mathrm{Sn}_{x} \mathrm{O}_{3}$. The ratio starts out near 100 and decreases to an asymptotic value of 1 . Clearly, reduction is less beneficial as $x$ increases. One explanation for this change in reduction behavior is that the defect responsible for production of conduction electrons changes from oxygen off-stoichiometry (i.e., $V_{\mathrm{O}}^{*}$ ) to cation off-stoichiometry (i.e., $[\mathrm{Sn}] /[\mathrm{Cd}]>1$ ). Thus the dopant level is fixed by the degree of cation off-stoichiometry and is therefore no longer a function of oxygen pressure. Thus the cation off-stoichiometry responsible for fixing the dopant level in the samples near the solution terminal point is a consequence of

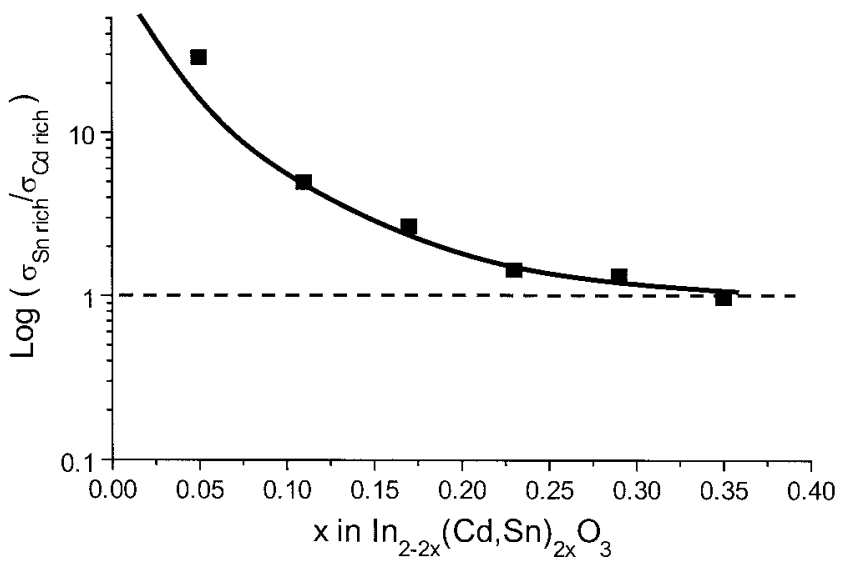

Fig. 5. $\log \left(\sigma_{\text {Sn-rich }} / \sigma_{\text {Cd-rich }}\right)$ vs $x$ in $\operatorname{In}_{2-2 x}(\mathrm{Cd}, \mathrm{Sn})_{2 x} \mathrm{O}_{3}$. 


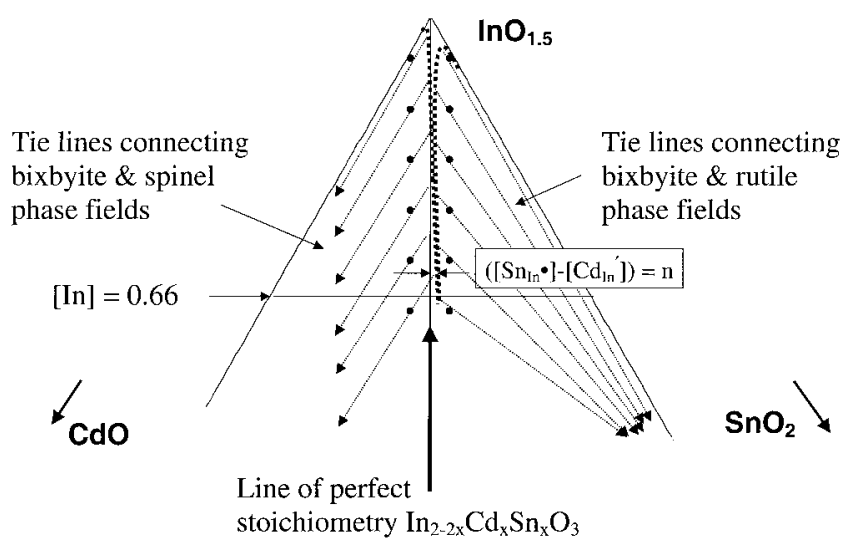

Fig. 6. Semiquantitative picture of the bixbyite phase field.

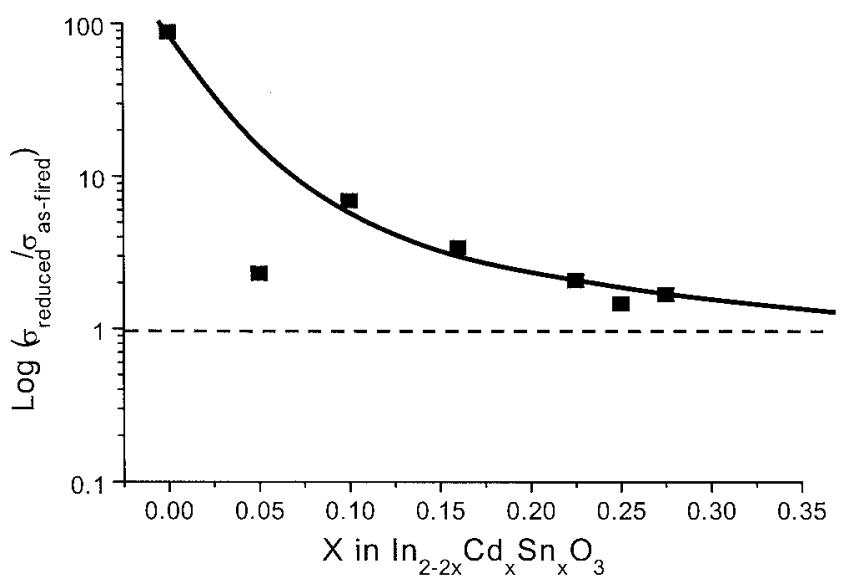

Fig. 7. $\log \left(\sigma_{\text {reduced }} / \sigma_{\text {as-fired }}\right)$ vs $x$ in specimens with nominal compositions given by $\operatorname{In}_{2-2 x} \mathrm{Cd}_{x} \mathrm{Sn}_{x} \mathrm{O}_{3}$.

the location of the phase boundary for the bixbyite phase field shown in Fig. 6.

Figure 8 shows thermopower data for as-fired and reduced specimens of nominal composition $\operatorname{In}_{2-2 x} \mathrm{Cd}_{x} \mathrm{Sn}_{x} \mathrm{O}_{3}$. All samples have negative Seebeck coefficients and are therefore n-type. The thermopower magnitude decreases sharply at first and then gradually approaches an asymptotic value near $-34.5 \mu \mathrm{V} / \mathrm{K}$ for as-fired samples and $-29.5 \mu \mathrm{V} / \mathrm{K}$ for reduced samples. The decrease in the thermopower magnitude correlates with the increase in conductivity shown in Fig. 4.

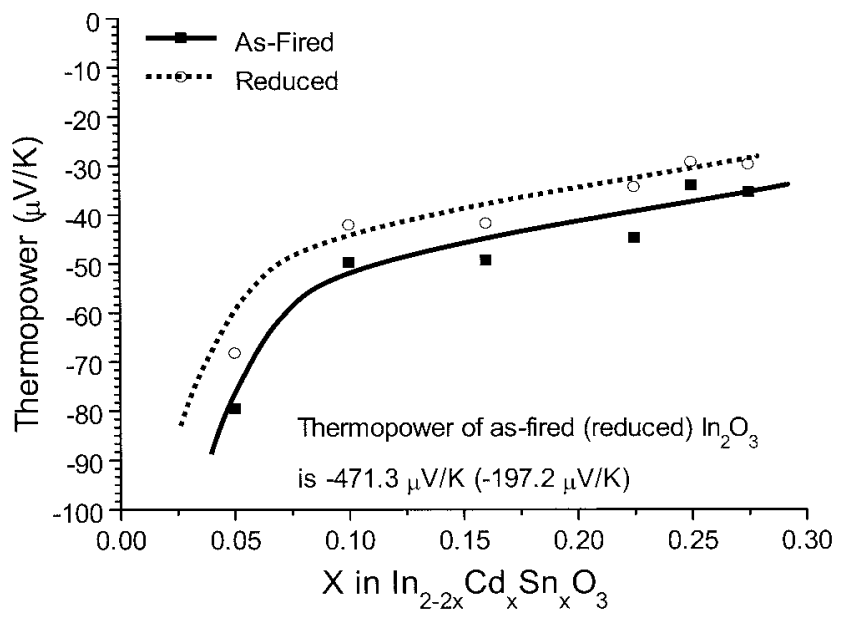

Fig. 8. Thermopower for reduced and as-fired specimens with nominal compositions given by $\mathrm{In}_{2-2 x} \mathrm{Cd}_{x} \mathrm{Sn}_{x} \mathrm{O}_{3}$.

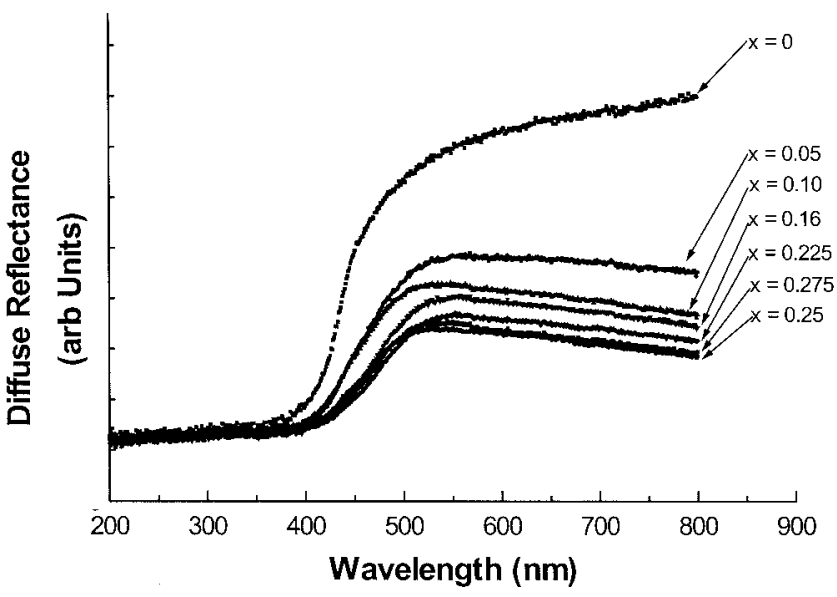

Fig. 9. Diffuse reflectance versus wavelength for specimens with nominal composition given by $\mathrm{In}_{2-2 x} \mathrm{Cd}_{x} \mathrm{Sn}_{x} \mathrm{O}_{3}$.

Figure 9 shows the diffuse reflectance spectra for single-phase bixbyite samples with nominal stoichiometry given by $\mathrm{In}_{2-2 x} \mathrm{Cd}_{x} \mathrm{Sn}_{x} \mathrm{O}_{3}$. Transparency decreases as $x$ increases. This may be a consequence of the increase in carrier density suggested by the decreasing thermopower magnitude with increasing $x$ shown in Fig. 8. Figure 10 shows the estimated optical gaps derived from diffuse reflectance spectra like that shown in Fig. 9 for samples prepared with nominal compositions $\mathrm{In}_{2-2 x} \mathrm{Cd}_{x} \mathrm{Sn}_{x} \mathrm{O}_{3}$. The optical gap remains relatively constant at $3.0 \mathrm{eV}$ across the solution. Reduction appears to increase the optical gap by about $0.1 \mathrm{eV}$ on average. Given that the optical gaps are determined from an estimate of the absorption edge and are only precise to $0.1 \mathrm{eV}$, this increase may or may not be significant. It is interesting to note, however, that the increase in optical gap shown in Fig. 10 correlates with the increase in carrier density after reduction shown by the decrease in thermopower magnitude after reduction of the samples shown in Fig. 8. This may be evidence of a MossBurstein shift (i.e., the upward shift of the Fermi level with respect to the conduction band owing to the filling of states with increased dopant level). ${ }^{29,30}$

\section{Conclusions}

A large TCO solid solution $\operatorname{In}_{2-2 x}(\mathrm{Cd}, \mathrm{Sn})_{2 x} \mathrm{O}_{3}$ possessing the $\mathrm{InO}_{1.5}$ bixbyite crystal structure has been discovered in the $\mathrm{CdO}-\mathrm{InO}_{1.5}-\mathrm{SnO}_{2}$ system, in which up to $34 \%$ of the element In present in $\mathrm{InO}_{1.5}$ can be replaced with a combination of $\mathrm{Cd}$ and $\mathrm{Sn}$. Electrical and X-ray data suggest that the solution is inherently

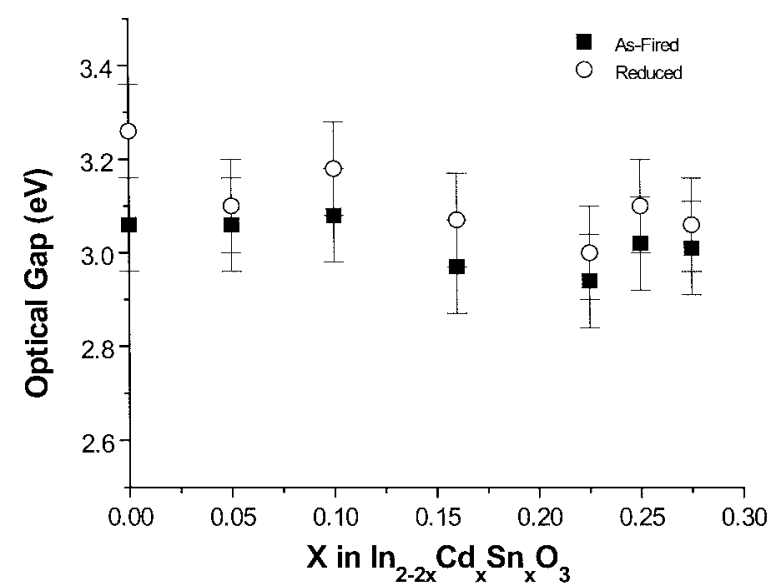

Fig. 10. Optical gap estimated from absorption edge (measured in diffuse reflectance) vs $x$ for specimens with nominal composition given by $\mathrm{In}_{2-2 x} \mathrm{Cd}_{x} \mathrm{Sn}_{x} \mathrm{O}_{3}$. 
n-type by virtue of the location of the bixbyite phase field within this system. That is, for $x$ greater than a few hundredths, the bixbyite phase exists only for $[\mathrm{Sn}] /[\mathrm{Cd}]>1.0$. At very small values of $x$ (e.g., $x<0.01$ ) the bixbyite phase field exists for $[\mathrm{Sn}] /[\mathrm{Cd}]<1.0$; however, the insulating behavior of these compositions suggests that the excess $\mathrm{Cd}_{\text {In }}^{\prime}$ is ionically compensated, perhaps by oxygen vacancies, rather than being electronically compensated by holes. It is the location of the bixbyite phase field within the $\mathrm{CdO}-\mathrm{InO}_{1.5}-\mathrm{SnO}_{2}$ system that governs the electrical and optical property variation. Since the phase boundary of $\mathrm{In}_{2-2 x}(\mathrm{Cd}, \mathrm{Sn})_{2 x} \mathrm{O}_{3}$ curves to the right of the line defined by $\mathrm{In}_{2-2 x} \mathrm{Cd}_{x} \mathrm{Sn}_{x} \mathrm{O}_{3}$, thermopower magnitude decreases (carrier density increases), conductivity increases, and transparency decreases as a consequence of free carrier absorption. Furthermore, the location of the bixbyite phase field suggests that any attempt at producing a p-type bixbyite TCO in this system must be done either through a metastable synthesis route or perhaps by exposing Cd-rich specimens (which only exist for very small $x$ ) to high oxygen pressures in hope of generating holes.

\section{References}

${ }^{1}$ N. R. Lyman, "Transparent Electronic Conductors"; pp. 201-31 in Electrochemical Society Proceedings, Vol. 90-92, Proceedings of the Symposium on Electrochromic Materials. Edited by M. K. Carpenter and D. A. Corrigan. Electrochemical Society, Pennington, NJ, 1990.

${ }^{2} \mathrm{X}$. Wu, T. J. Coutts, and W. P. Mulligan, "Properties of Transparent Conducting Oxides Formed from $\mathrm{CdO}$ and $\mathrm{ZnO}$ Alloyed with $\mathrm{SnO}_{2}$ and $\mathrm{In}_{2} \mathrm{O}_{3}$," J. Vac. Sci. Technol. A, 15 [3] 1057-62 (1997).

${ }^{3}$ A. J. Nozik, "Optical and Electrical Properties of $\mathrm{Cd}_{2} \mathrm{SnO}_{4}$ : A Defect Semiconductor," Phys. Rev. B, 6 [2] 453 (1972).

${ }^{4}$ R. B. H. Tahar, T. Ban, Y. Ohya, and Y. Takahashi, "Tin Doped Indium Oxide Thin Films: Electrical Properties," J. Appl. Phys., 83 [5] 2631-45 (1998).

${ }^{5}$ R. D. Shannon, J. L. Gillson, and R. J. Bouchard, "Single Crystal Synthesis and Electrical Properties of $\mathrm{CdSnO}_{3}, \mathrm{Cd}_{2} \mathrm{SnO}_{4}, \mathrm{In}_{2} \mathrm{TeO}_{6}$, and $\mathrm{CdIn}_{2} \mathrm{O}_{4}, " J$. Phys. Chem Solids, 38, 877 (1977)

${ }^{6}$ T. O. Mason and H. Kawazoe, "Transparent Conducting Oxides: New Materials", pp. 228-36 in MRS Workshop on Transparent Conducting Oxides, Vol. 1. Edited by D. S. Ginley, T. Coutts, T. Mason. and C. Bright. Materials Research Society, Warrendale, PA, 2000

${ }^{7}$ H. Kawazoe, M. Yasukawa, H. Hyodo, M. Kurita, H. Yanagi, and H. Hosono, "P-Type Electrical Conduction in Transparent Films of $\mathrm{CuAlO}_{2}, "$ Nature (London), 389 [6654] 939-42 (1997).

${ }^{8}$ N. Duan, A. W. Sleight, M. K. Jayaraj, and J. Tate, "Transparent p-Type Conducting $\mathrm{CuScO}_{2+x}$ Films," Appl. Phys. Lett., 77 [9] 1325-26 (2000).
${ }^{9}$ M. Joseph, H. Tabata, and T. Kawai, "p-Type Electrical Conduction in ZnO Thin Films by Ga and N Codoping," Jpn. J. Appl. Phys., 38 [11A] L1205-L1207 (1999).

${ }^{10} \mathrm{~T}$. Yamamoto and H. Katayama-Yoshida, "Solution Using a Codoping Method to Unipolarity for the Fabrication of p-Type ZnO," Jpn. J. Appl. Phys. 38 [2B] L166-L169 (1999).

${ }^{11}$ G. B. Palmer, K. R. Poeppelmeier, and T. O. Mason, "Conductivity and Transparency of $\mathrm{ZnO} / \mathrm{SnO}_{2}$-Cosubstituted $\mathrm{In}_{2} \mathrm{O}_{3}$," Chem. Mater., 9, 3121 (1997).

${ }^{12}$ A. Ambrosini, S. Malo, K. R. Poeppelmeier, M. Lane, C. Kannewurf, and T. O. Mason, "Zinc-Doping in Cosubstituted $\mathrm{In}_{2-2 x} \mathrm{Sn}_{x} \mathrm{Zn}_{x} \mathrm{O}_{3-\delta}$," Chem. Mater., in press.

${ }^{13}$ R. A. Winholz and J. D. Almer, Peakfit, Fortran Program, Northwestern University, Evanston, IL, 1991.

${ }^{14}$ D. Keszler, D. Cahen, and J. Ibers, POLSQ, Fortran Program, Northwestern University, Evanston, IL, 1984.

${ }^{15}$ F. M. Smits, "Measurements of Sheet Resistivities with the Four-Point Probe," Bell Syst. Tech. J., 37 [3] 711 (1958).

${ }^{16}$ D. S. McLachlan, M. Blaszkiewicz, and R. E. Newnham, "Electrical Resistivity of Composites," J. Am. Ceram. Soc., 73 [8] 2187 (1990).

${ }^{17}$ B. S. Hong, S. J. Ford, and T. O. Mason, "Equilibrium Electrical Property Measurements in Electroceramics," Key Eng. Mater., 125, 163-86 (1997).

${ }^{18}$ J. Hwang, "Interfacial Electrical/Dielectric Phenomena in Nanoscale Ceramics"; Ph.D. Thesis. Northwestern University, Evanston, IL, 1996.

${ }^{19}$ H. G. Hecht, "The Present Status of Diffuse Reflectance Theory"; pp. 1-26 in Modern Aspects of Reflectance Spectroscopy. Edited by W. W. Wendlandt. Plenum Press, New York, 1968.

${ }^{20}$ D. R. Kammler, T. O. Mason, and K. R. Poeppelmeier, "Phase Relationships, Transparency, and Conductivity in the Cadmium Indate-Cadmium Stannate System," Chem. Mater., 12 [7] 1954-60 (2000).

${ }^{21}$ R. D. Shannon, "Revised Effective Ionic Radii and Systematic Studies of Interatomic Distances in Halides and Chalcogenides," Acta Crystallogr., A32 751 (1976).

${ }^{22}$ J. H. W. DeWit, G. V. Unen, and M. Lahey, "Electron Concentration and Mobility in $\mathrm{In}_{2} \mathrm{O}_{3}$, J. Phys. Chem. Solids, 38, 819-24 (1977).

${ }^{23}$ J. H. W. DeWit, "Structural Aspects and Defect Chemistry in $\mathrm{In}_{2} \mathrm{O}_{3}$, , J. Solid State Chem., 20, 143-48 (1977).

${ }^{24}$ J.-H. Hwang, D. D. Edwards, D. R. Kammler, and T. O. Mason, "Point Defects and Electrical Properties of Sn-Doped In-Based Transparent Conducting Oxides," Solid State Ionics, 129, 135-44 (2000).

${ }^{25}$ G. Frank and H. Köstlin, "Electrical Properties and Defect Model of Tin-Doped Indium Oxide Layers," Appl. Phys. A, 27, 197-206 (1982).

${ }^{26}$ M. Marezio, "Refinement of the Crystal Structure of $\operatorname{In}_{2} \mathrm{O}_{3}$ at two Wavelengths," Acta Crystallogr., 20, 723-28 (1966).

${ }^{27}$ L. V. Morozova and A. V. Komarov, "Interaction of the Oxides and Phase Relationships in the $\mathrm{In}_{2} \mathrm{O}_{3}-\mathrm{CdO}$ System," Russ. J. Inorg. Chem., 36 [1] 136-37 (1991)

${ }^{28}$ D. D. Edwards, "Phase Relations, Crystal Structures, and Electrical Properties of Select, Oxides in the Gallium-Indium-Tin Oxide System"; Doctoral Dissertation. Northwestern University, Evanston, IL, 1997.

${ }^{29}$ T. S. Moss, "The Interpretation of the Properties of Indium Antimonide," Proc. Phys. Soc. A, 382, 775 (1954).

${ }^{30}$ E. Burstein, "Anomalous Optical Absorption Limit in InSb," Phys. Rev., 93, 632 (1954). 